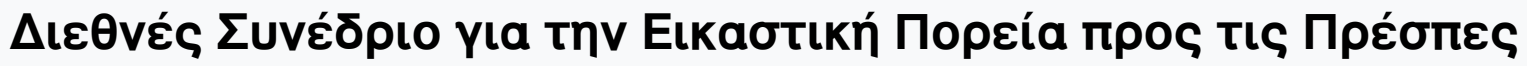

Tóp. 5 (2015)

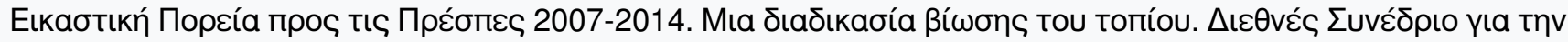

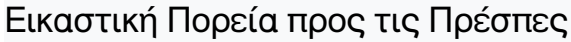

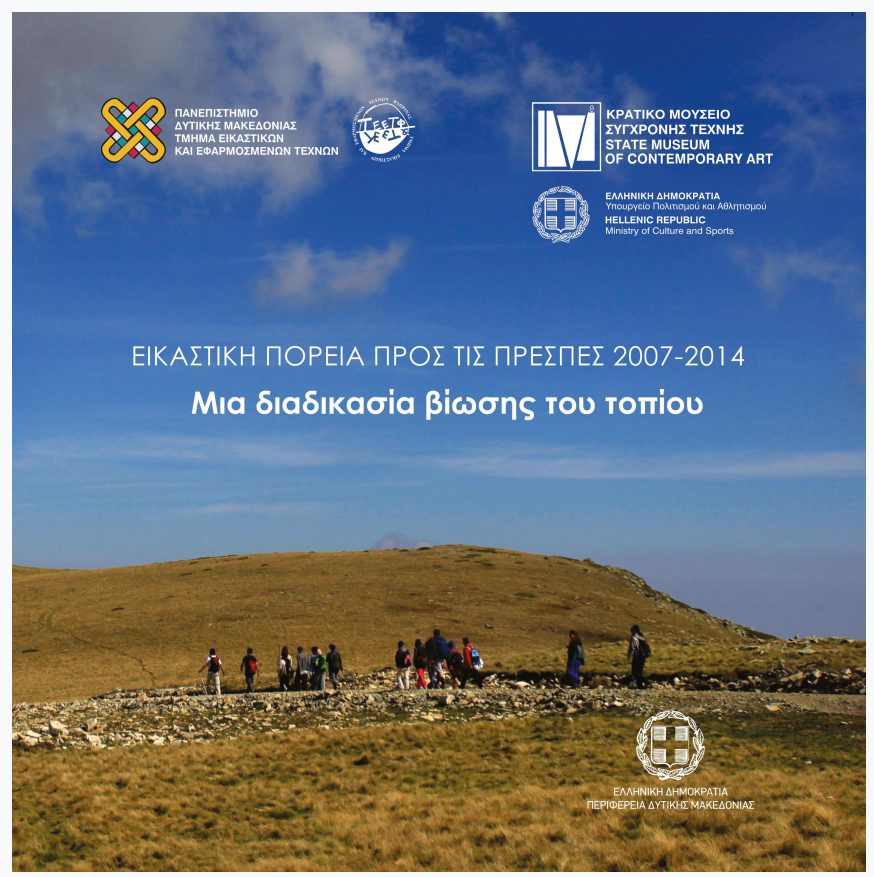

Паıठаүшүıкń Tou Tónou, Land Arts of the American West

\section{Bill Gilbert}

doi: $10.12681 /$ visualmarch.3076 
sers?

4. 10 (1)

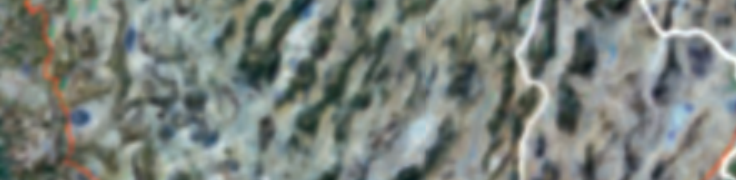
-

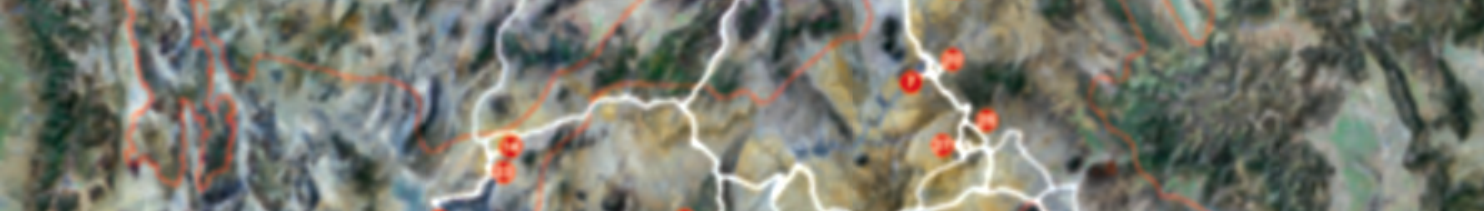
G) $124: 4$ 340

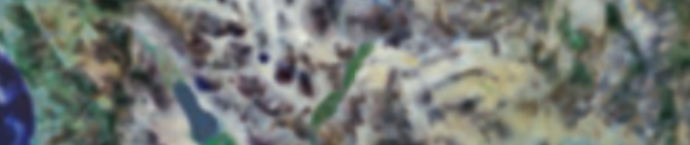

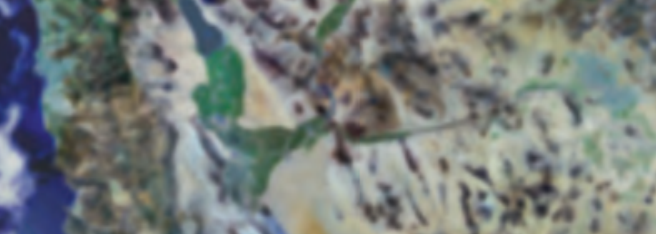

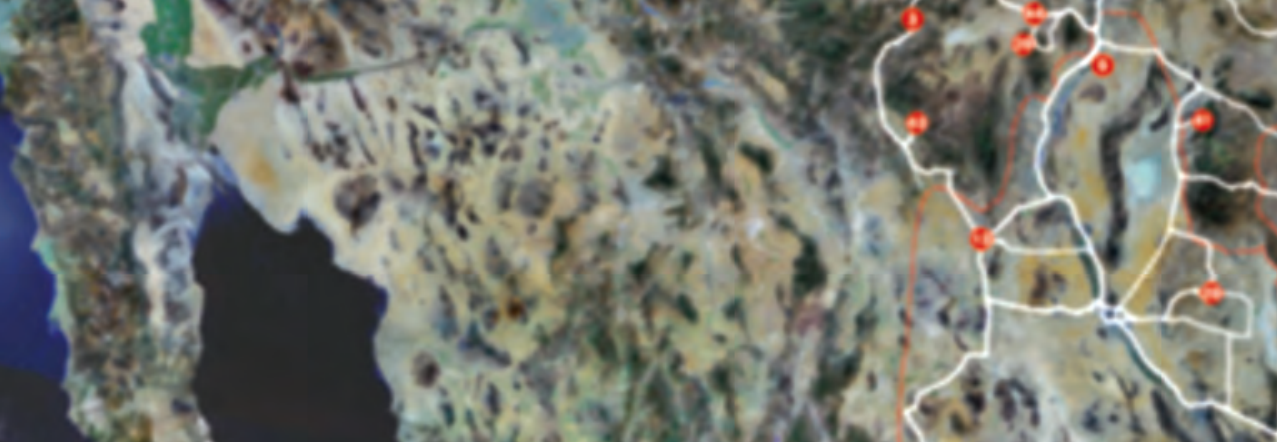
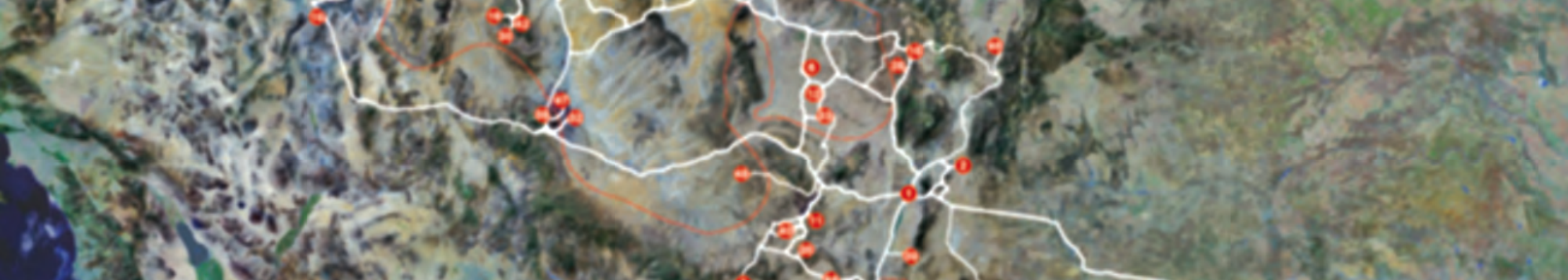

d
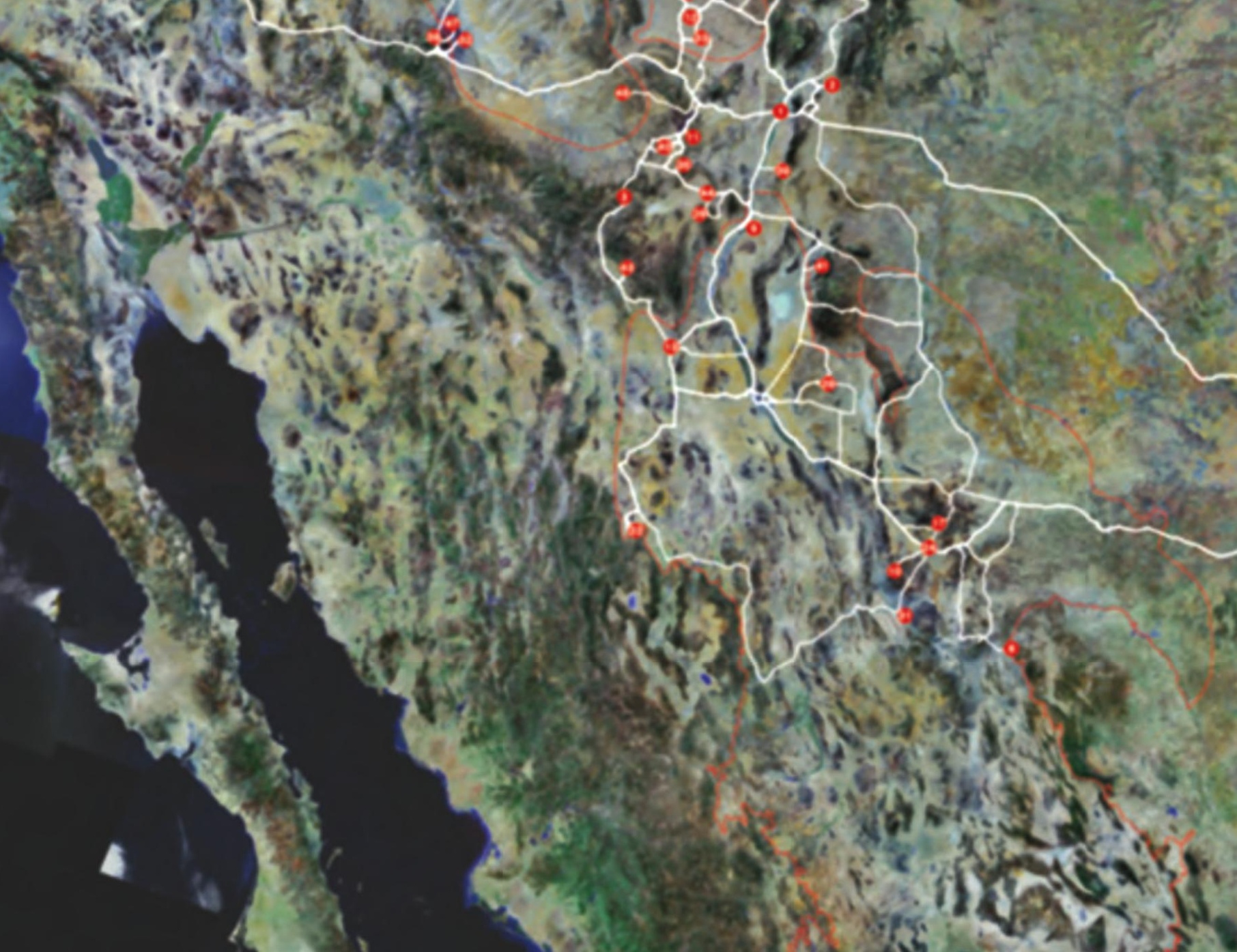

EIK. 1

EIK. 1 


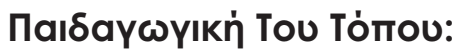 Land Arts of the American West}

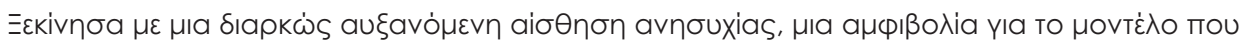

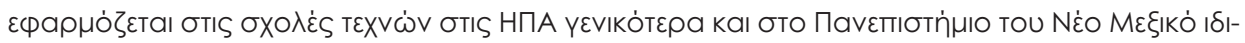

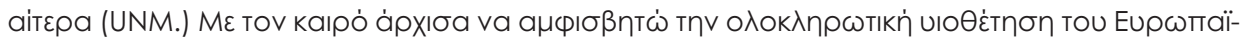

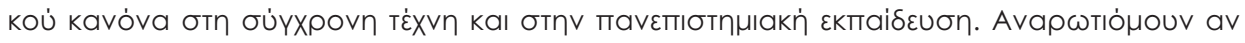

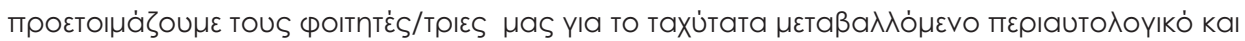

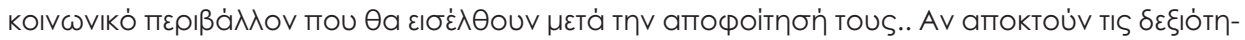

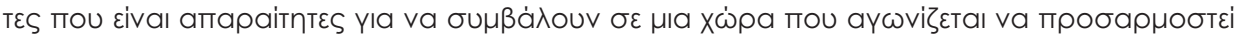

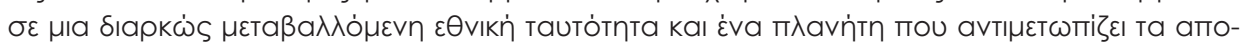

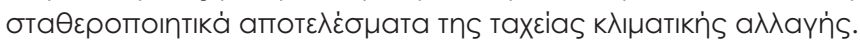

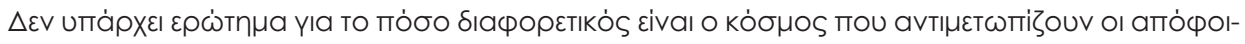

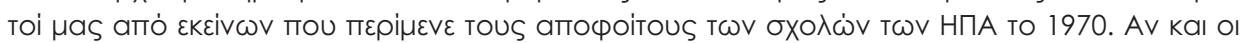

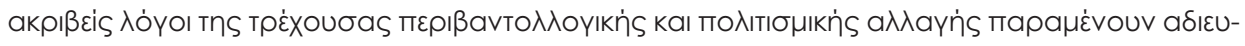

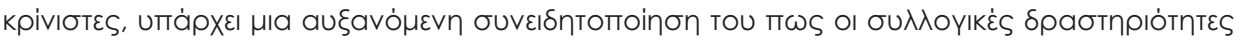

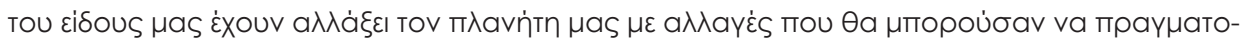

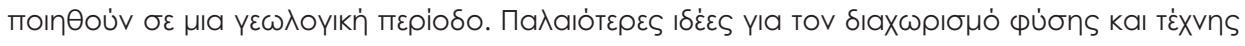

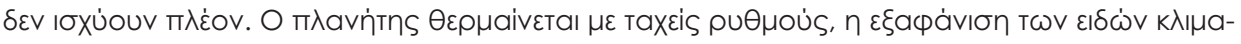

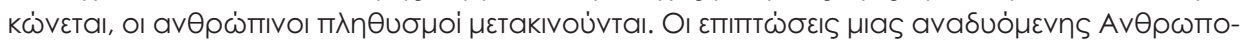

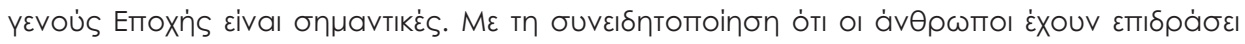

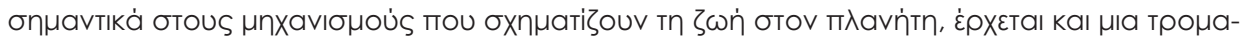

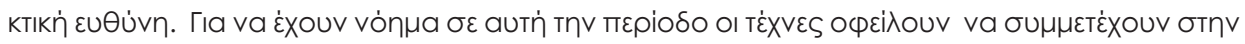

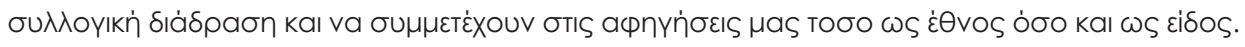

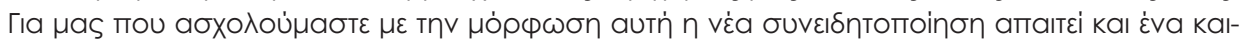

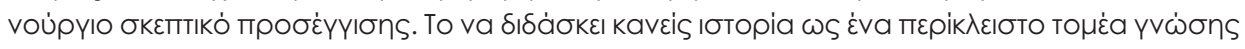

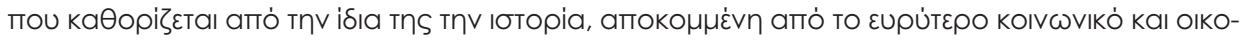

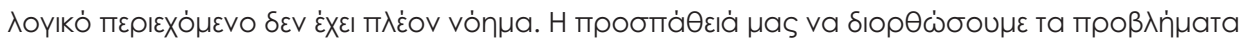

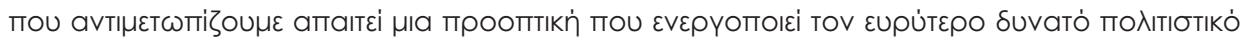

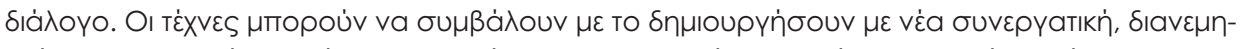

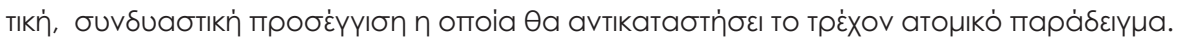

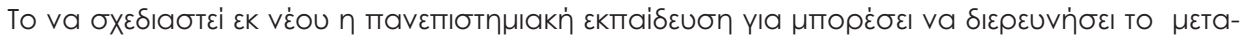

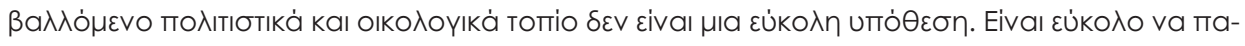

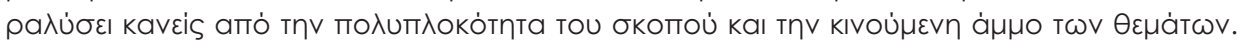

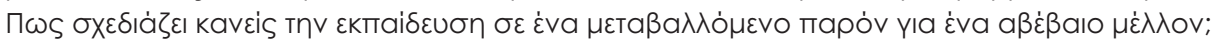

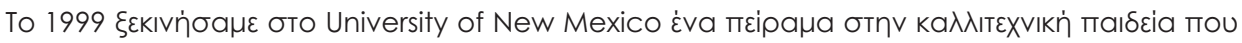

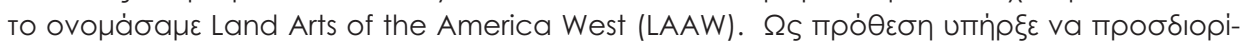

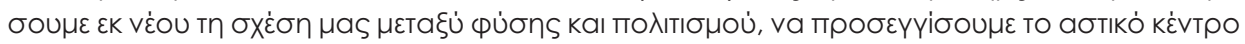

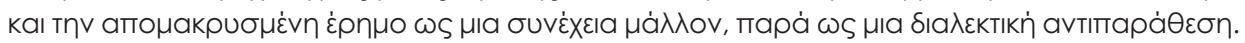

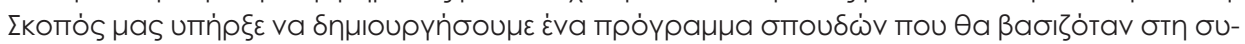

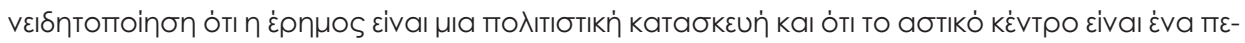

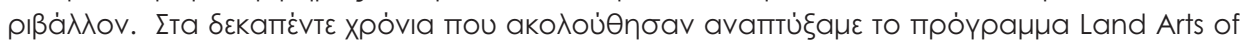

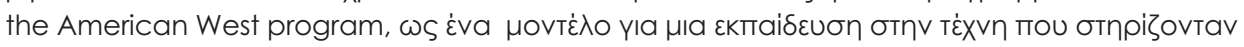

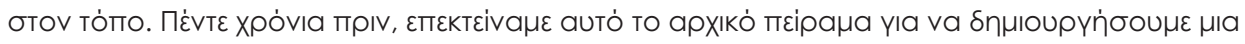

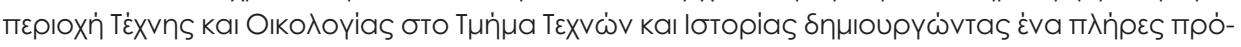

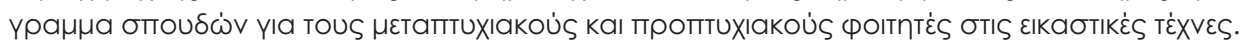




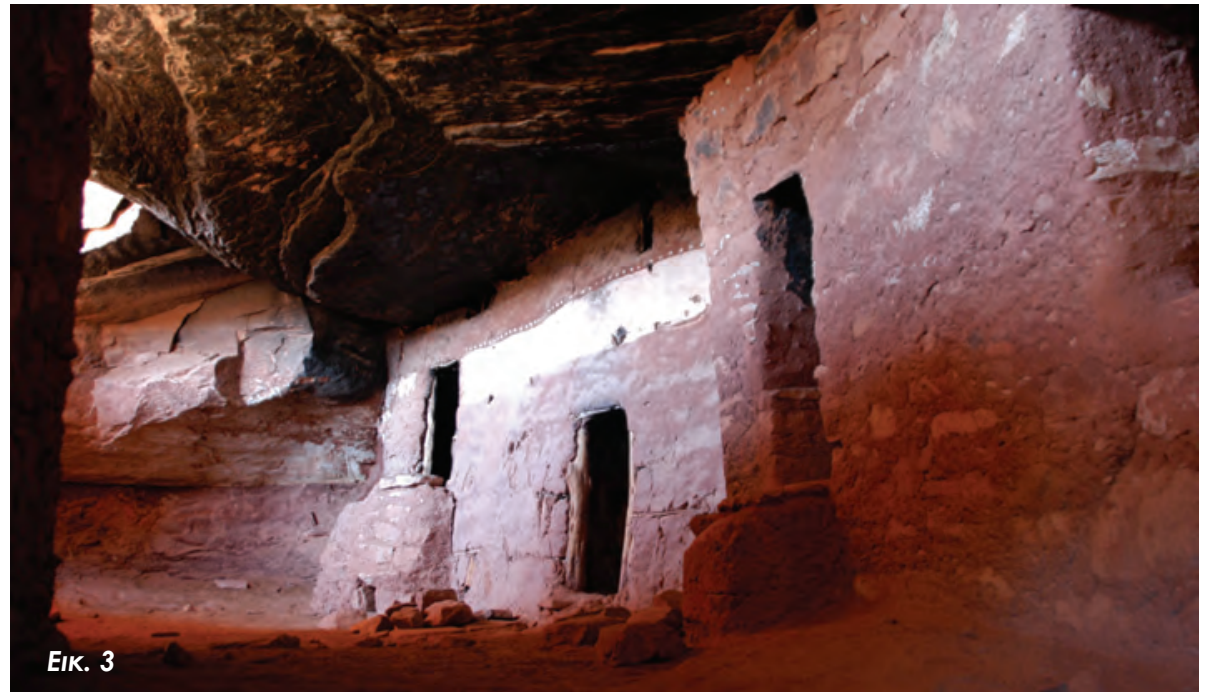

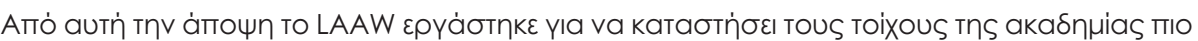

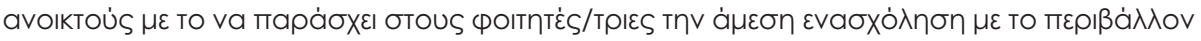

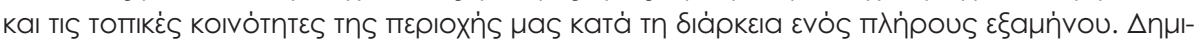

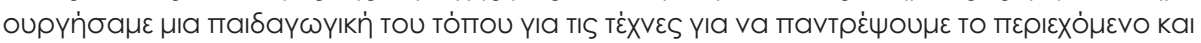

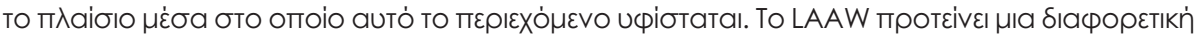

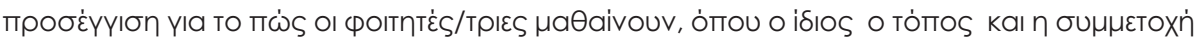

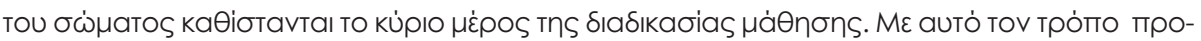

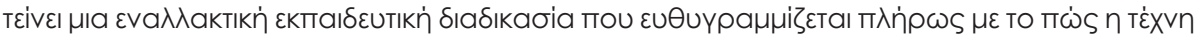

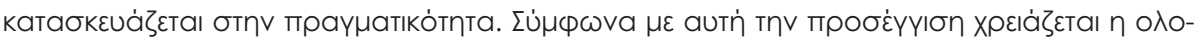

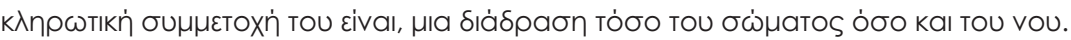

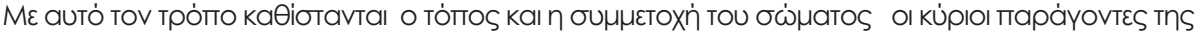

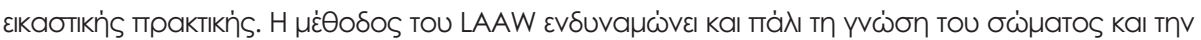

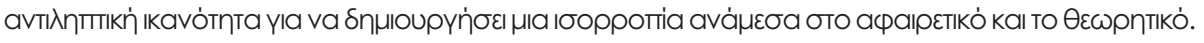

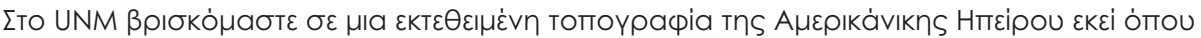

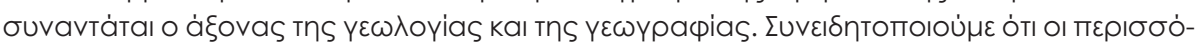

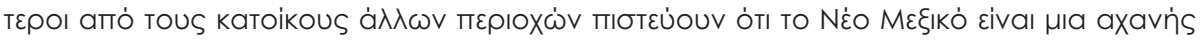

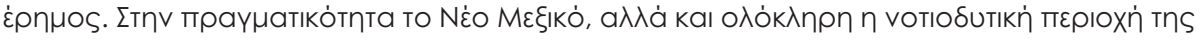

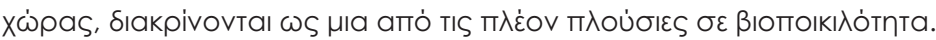

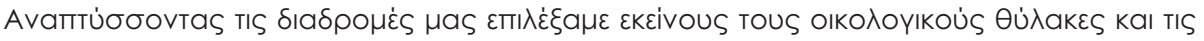

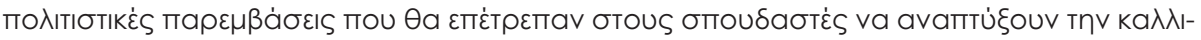

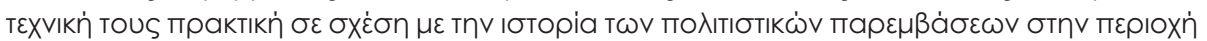

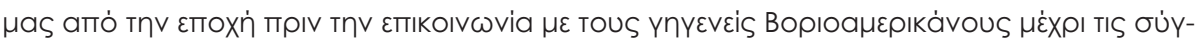

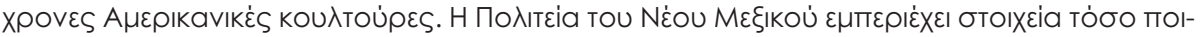

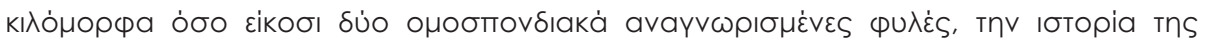

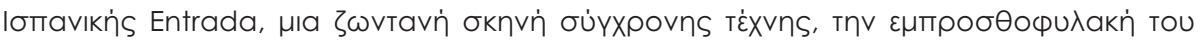

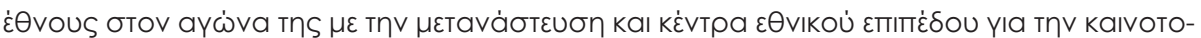

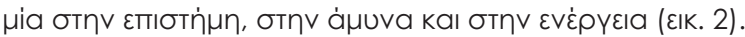

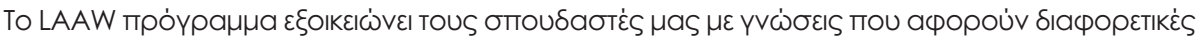

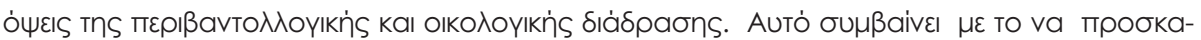

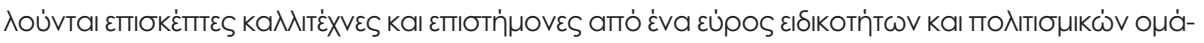

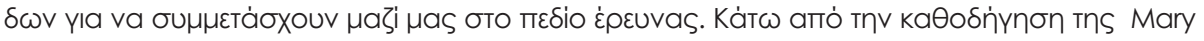

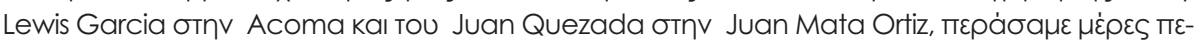

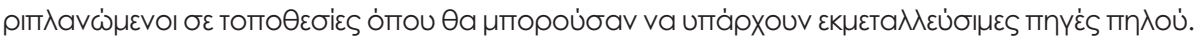

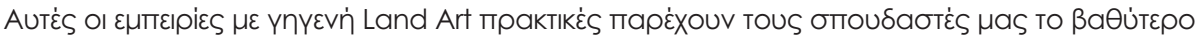

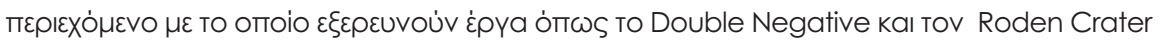




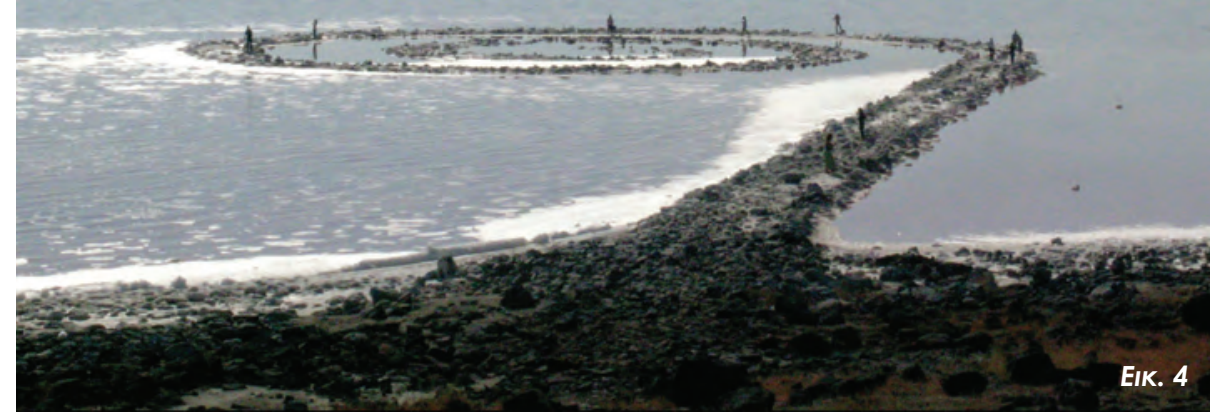

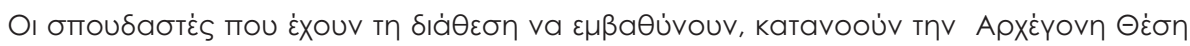

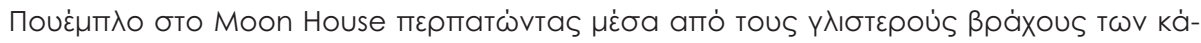

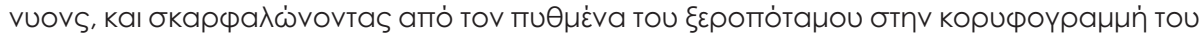

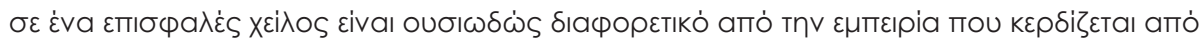
$\dot{\varepsilon} \vee \mathrm{B} ß \beta \lambda i \mathrm{o}(\varepsilon \mid k .3)$.

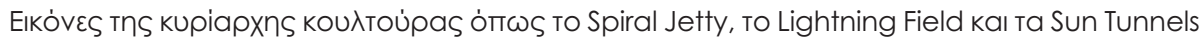

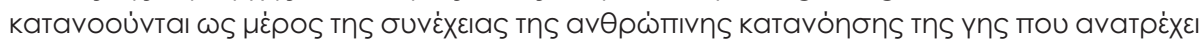

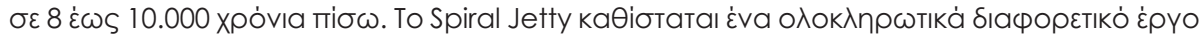

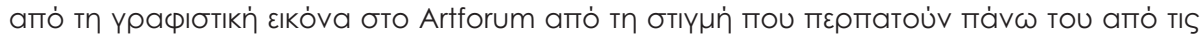

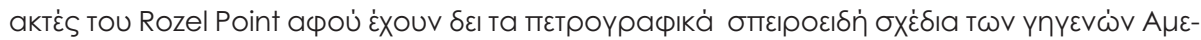

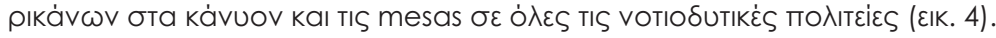

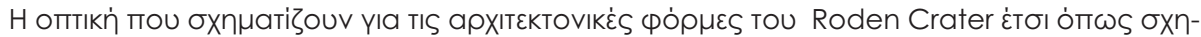

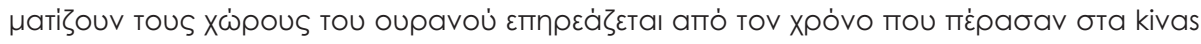

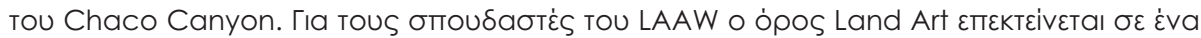

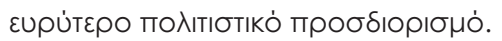

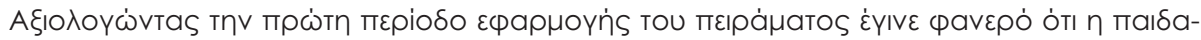

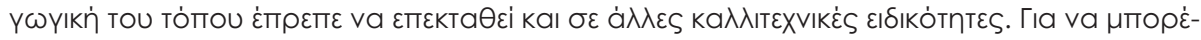

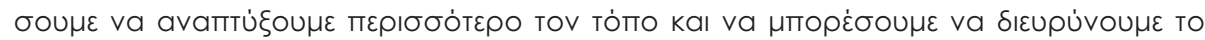

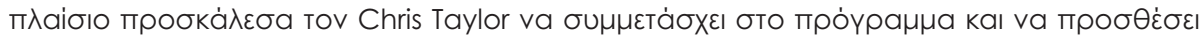

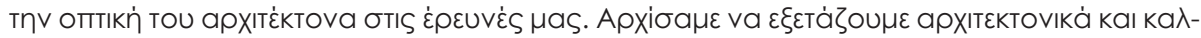

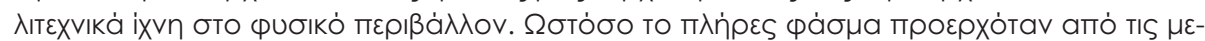

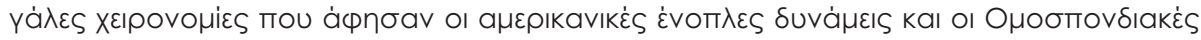

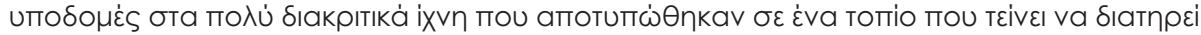

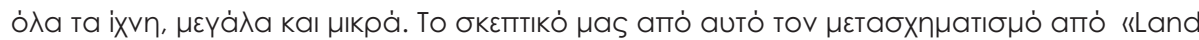

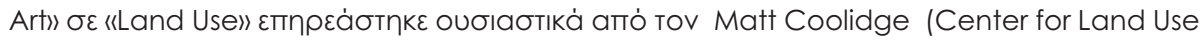

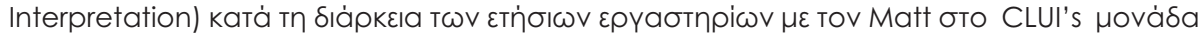
бто Wendover, Utah.

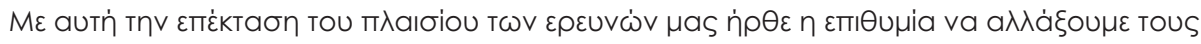

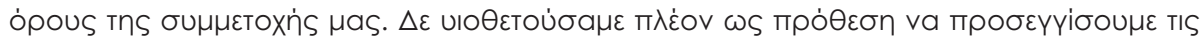

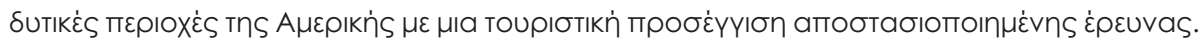
28. 

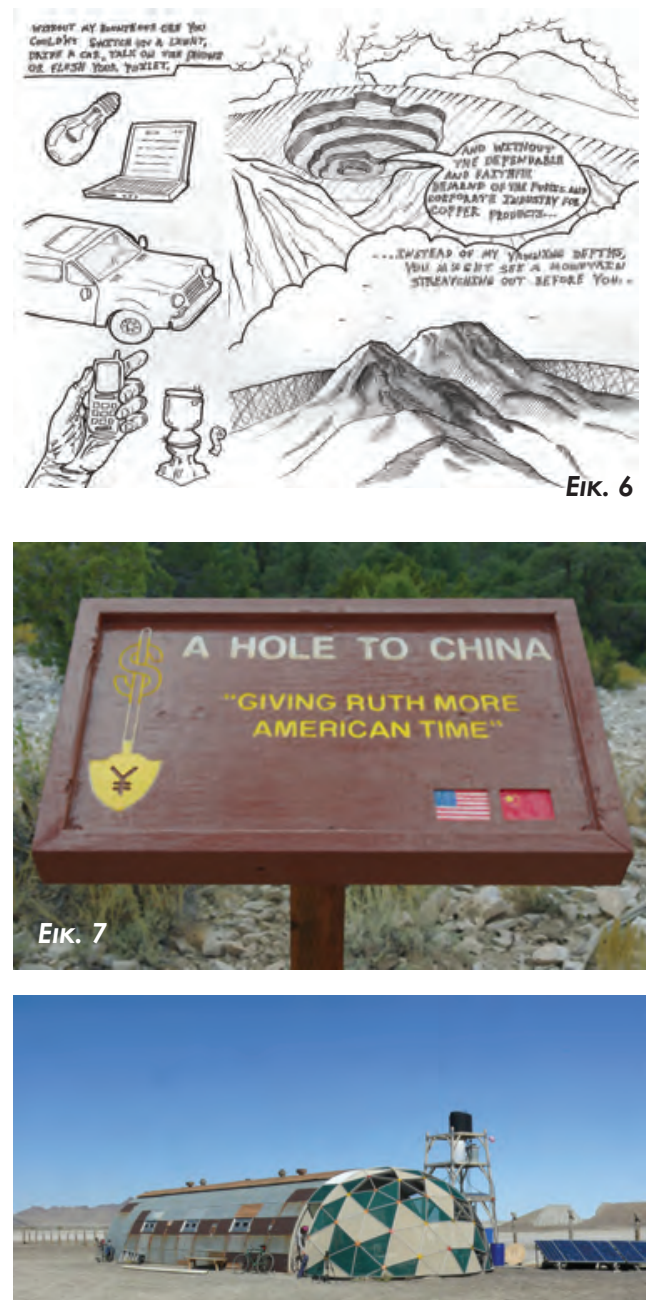

EIK. 8

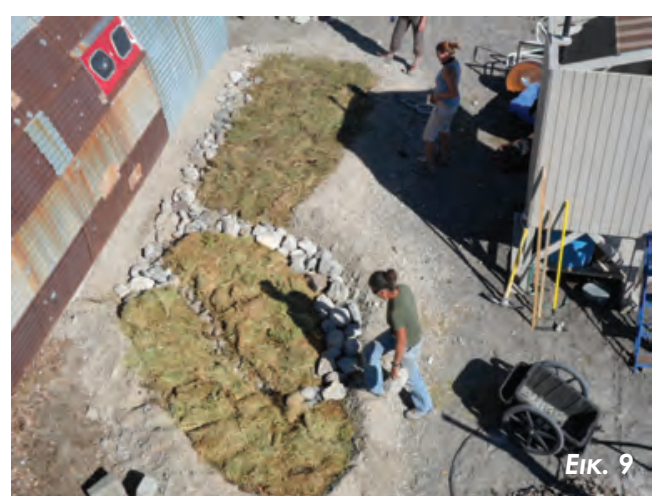

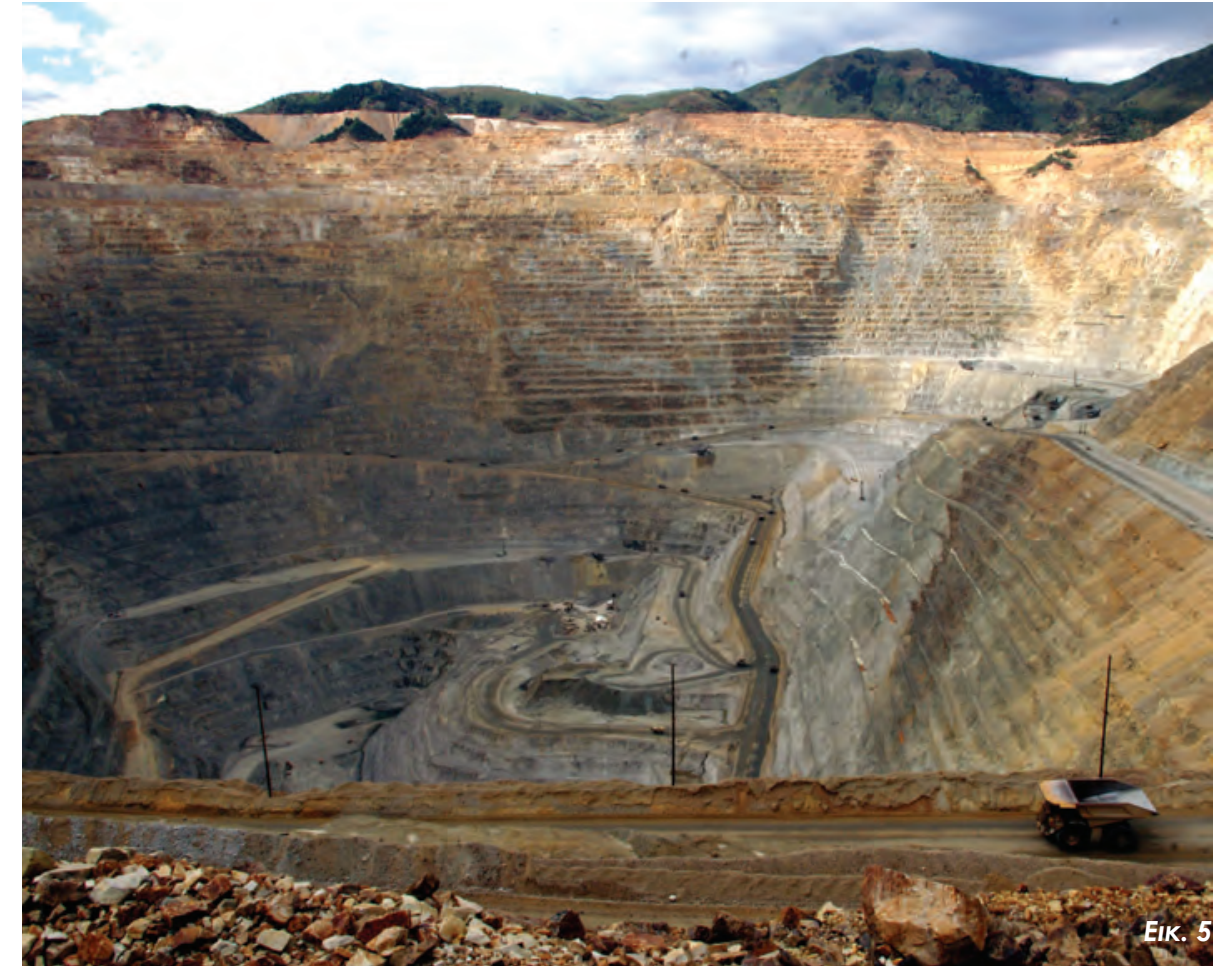

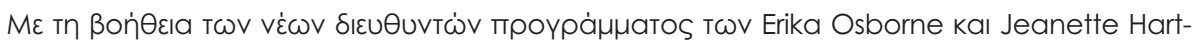

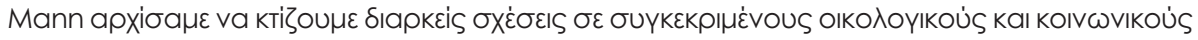

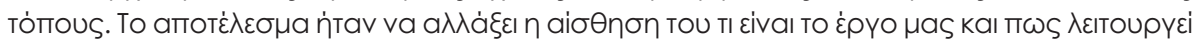

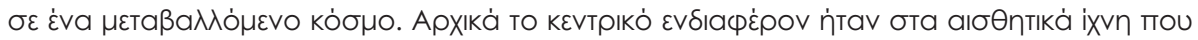

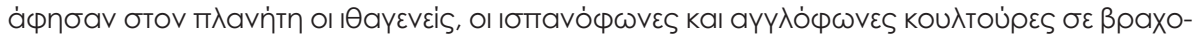

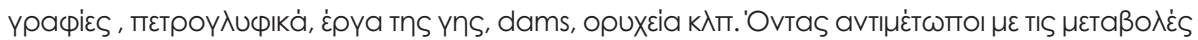

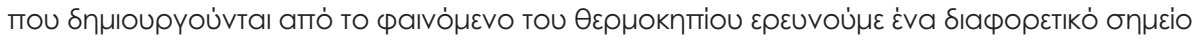

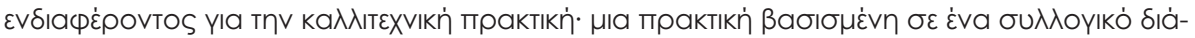

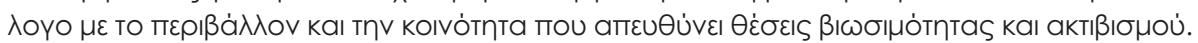

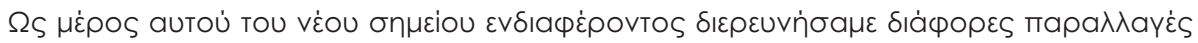

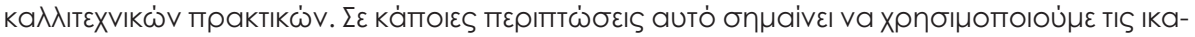

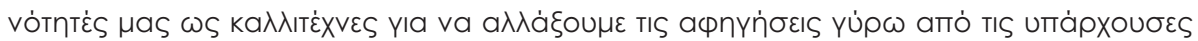

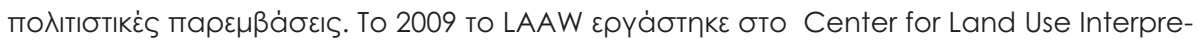

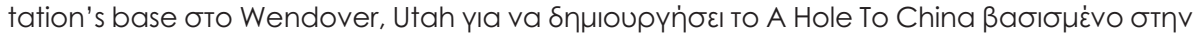

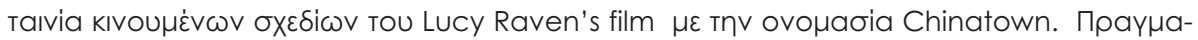

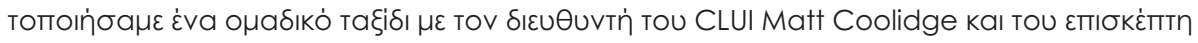

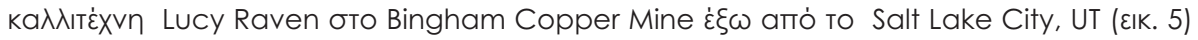

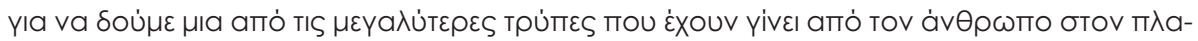

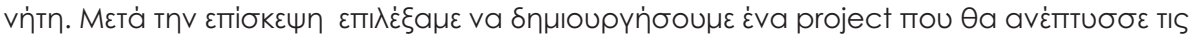

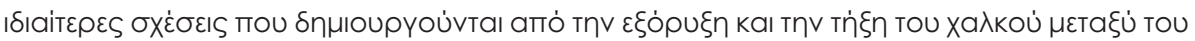

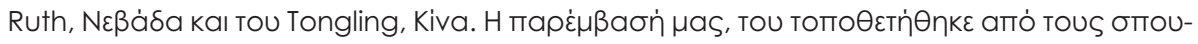

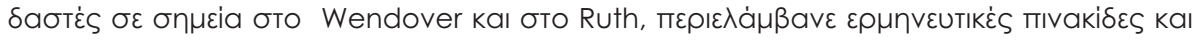

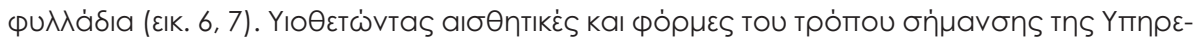

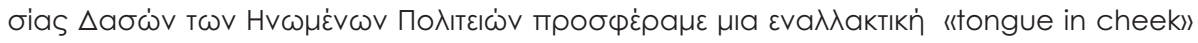

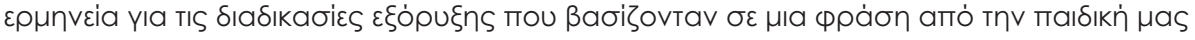

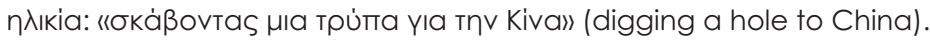

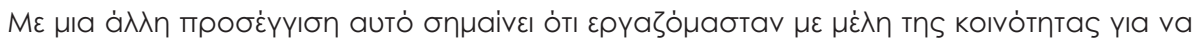

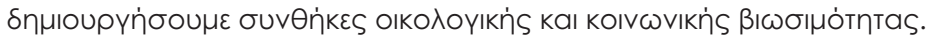



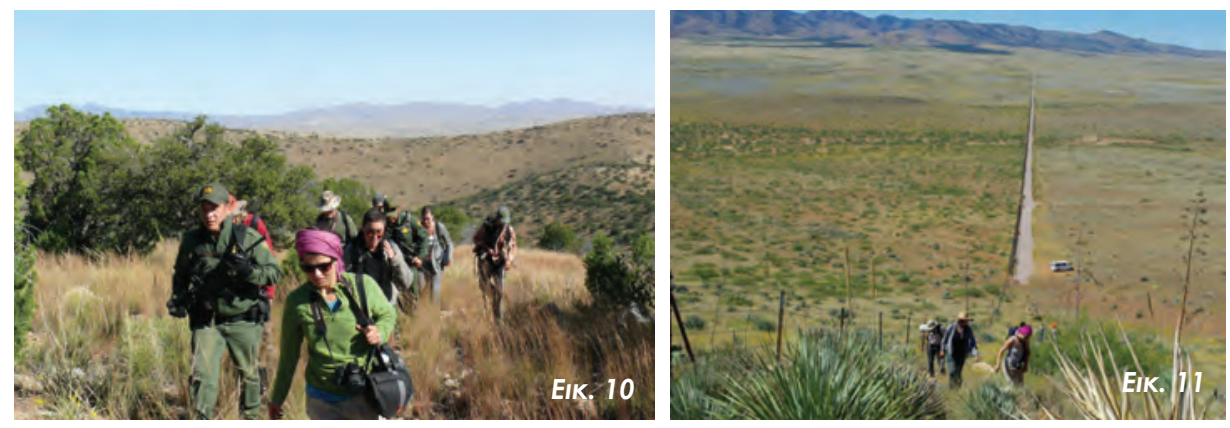

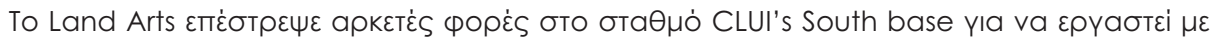

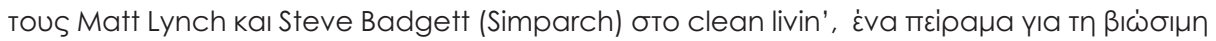

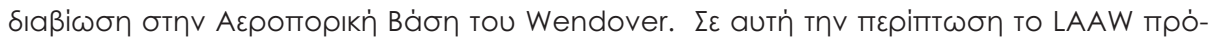

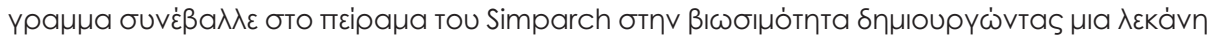

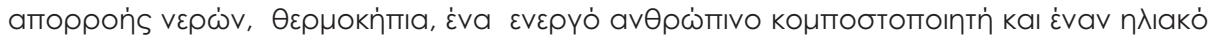

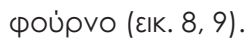

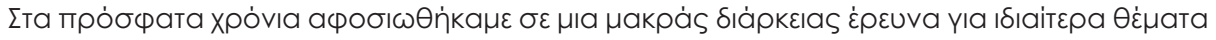

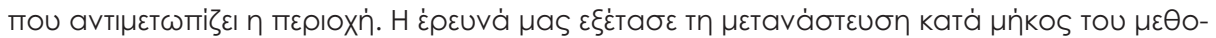

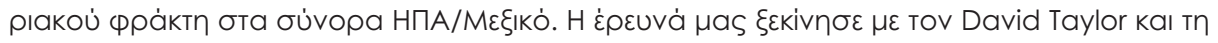

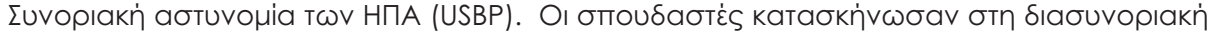

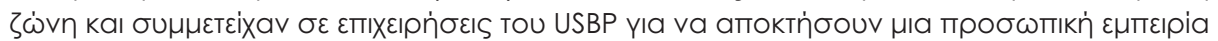

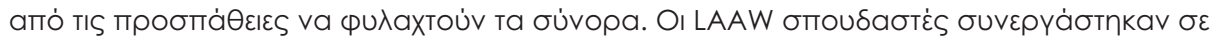

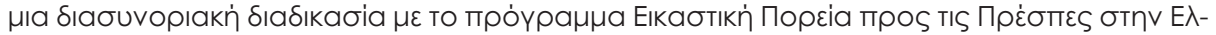

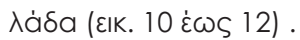

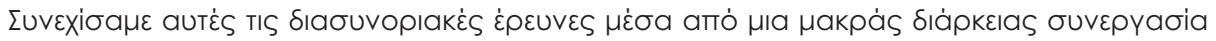

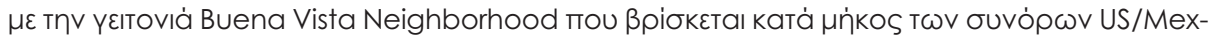

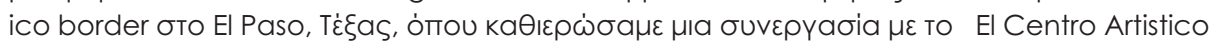

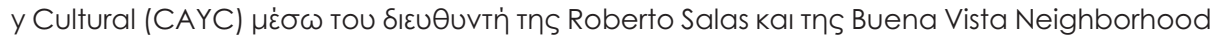

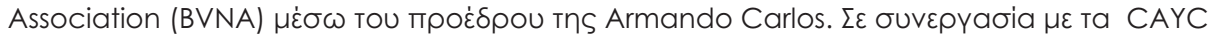

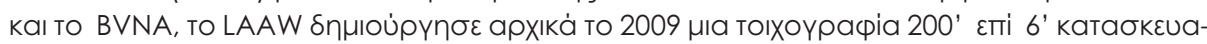

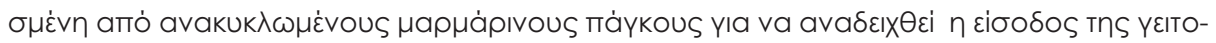

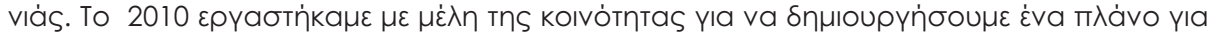

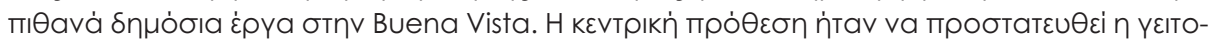

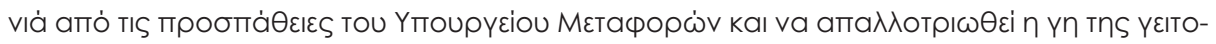

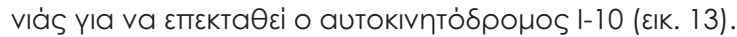

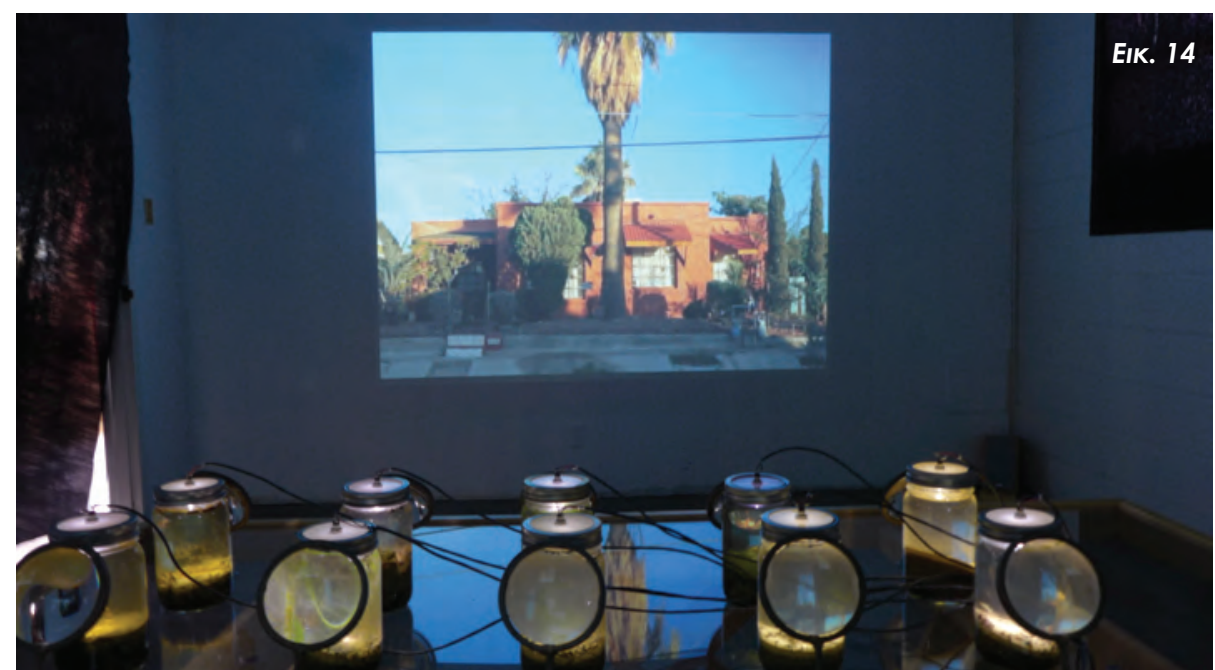

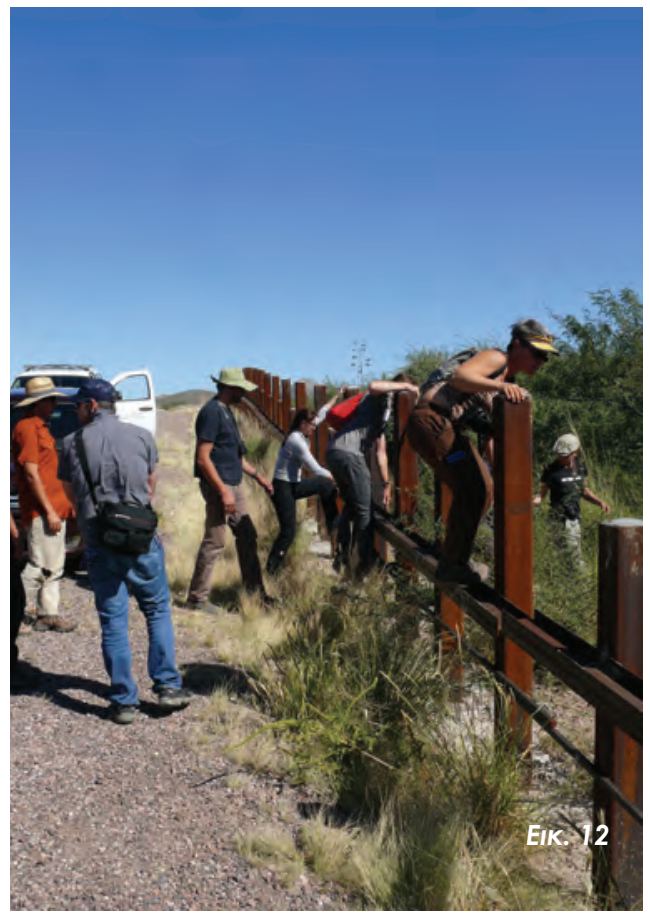

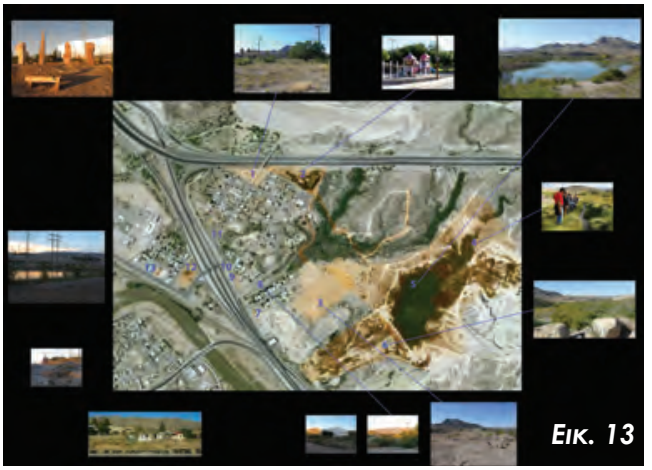



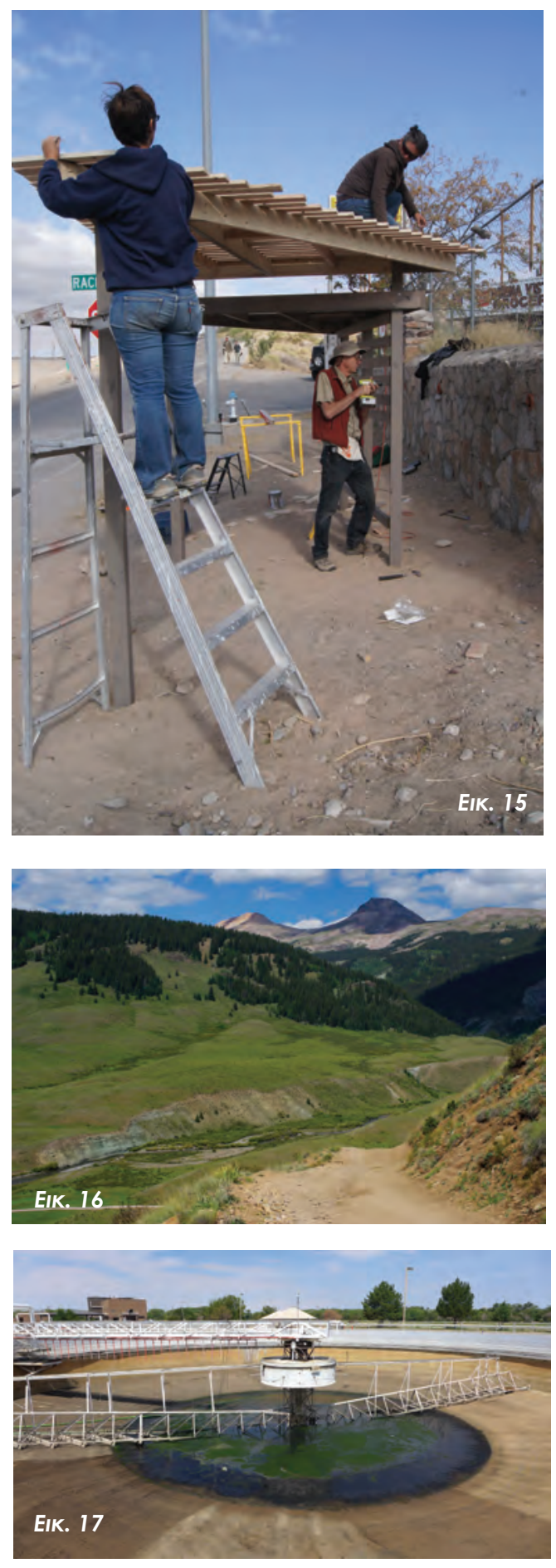

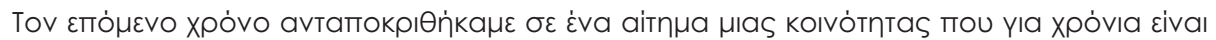

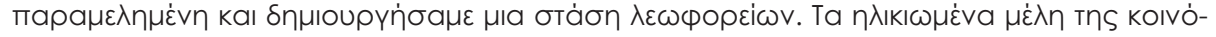

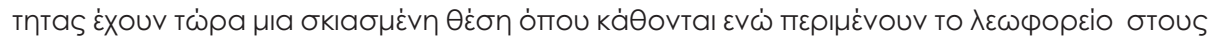

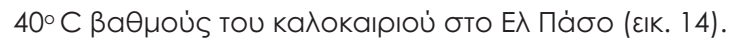

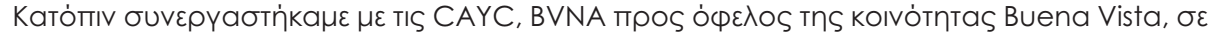

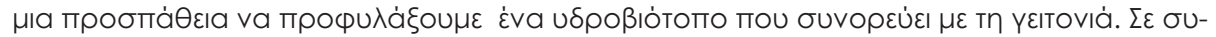

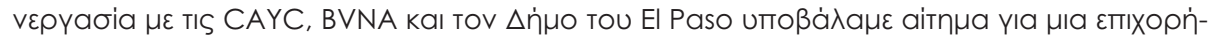

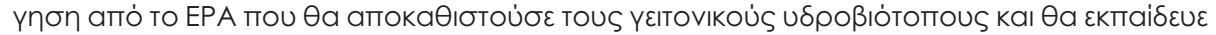

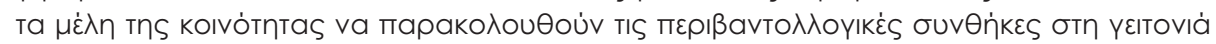

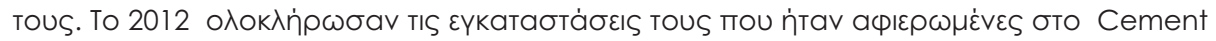
Lake project бто Center for Contemporary Art oтnv Santa Fe kaı oто Centro Artistico y Cultural бто El Paso (عIK. 15).

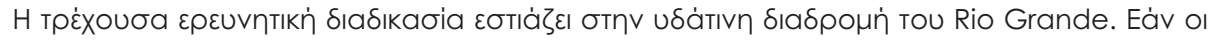

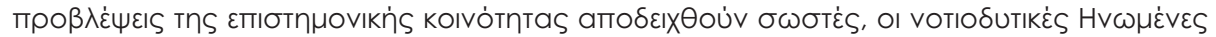

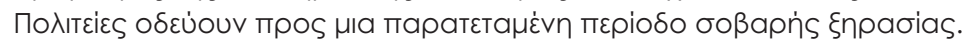

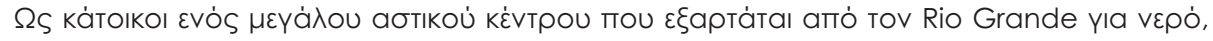

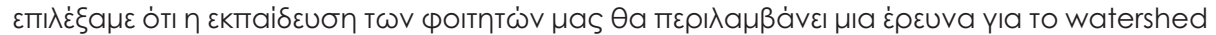

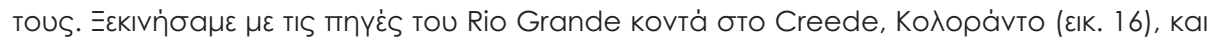

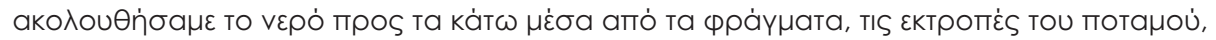

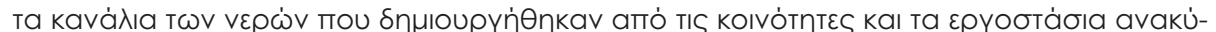

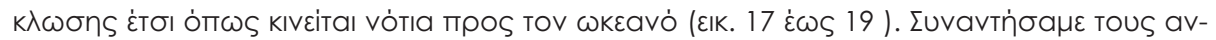

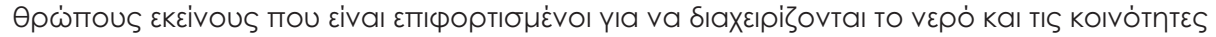

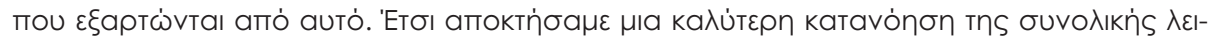

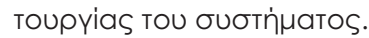

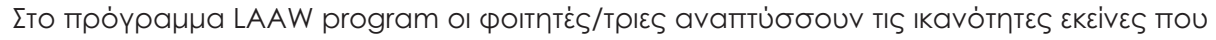

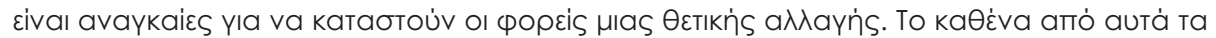

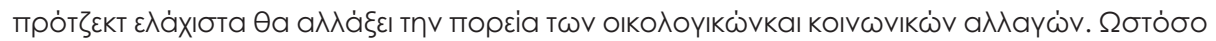

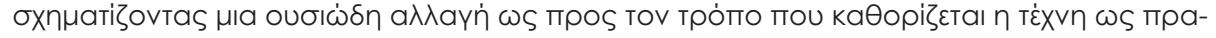

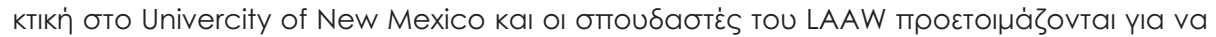

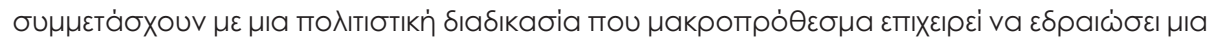

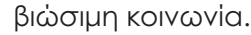

\section{Bill Gilbert}

¿Uvtoviotn's tou Land Arts of the American West

KaӨnYnтr's Department of Art \& Art History, University of New Mexico, HПA

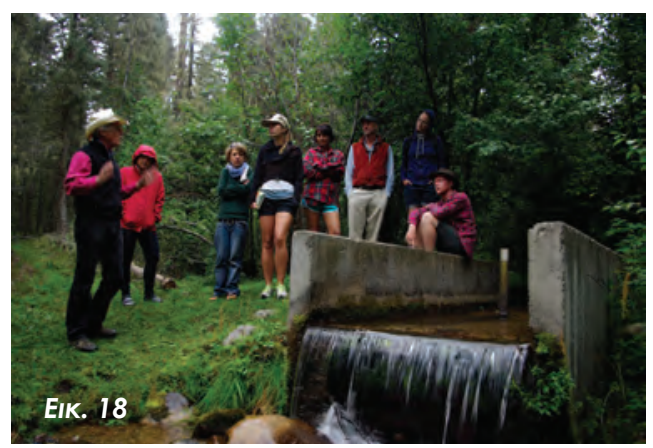

